\title{
Passive Smoking in Never-Smokers Is Associated With Increased Plasma Homocysteine Levels Analysis of NHANES III Data
}

\author{
Dong-Bin KIM, ${ }_{1}^{1} \mathrm{MD}$, Yong-Seog OH, ${ }^{1} \mathrm{MD}$, Ki-Dong Yoo, ${ }^{1} \mathrm{MD}$, Jong-Min LeE, ${ }^{1} \mathrm{MD}$, \\ Chan Seok PARK, ${ }^{1}$ MD, Sang-Hyun Ihm, ${ }^{1}$ MD, Sung Won JAng, ${ }^{1}$ MD, Byung Ju Shim,,${ }^{1}$ MD, \\ Hee-Yeol Kim, ${ }^{1}$ MD, Ki Bae Seung, ${ }^{1}$ MD, Tai-Ho RHo, ${ }^{1}$ MD, and Jae-Hyung KIM, ${ }^{1}$ MD
}

\section{SUMMARY}

Smoking is associated with increased plasma homocysteine levels, and both are associated with an increased risk of cardiovascular disease. However, little information is available on the effects of passive smoking on the level of homocysteine in nonsmokers. We analyzed the data of self-reported never-smokers (aged $\geq 20$ years, $n=$ 3,232), who were from the Third National Health and Nutrition Examination Survey. We quantified the passive nicotine exposure by dividing the never-smokers into quartiles as based on the serum cotinine values. Multiple linear and logistic regression models were used to determine any independent relationships between serum cotinine concentration and levels of homocysteine, vitamin B12, and folate. An elevated homocysteine level was defined as a concentration greater than the 80th percentile. A reduced folate or vitamin B12 level was defined as a concentration less than the 20th percentile.

After adjusting for age, gender, body mass index, race, folate and vitamin B12 levels, increased cotinine levels (quartile III and IV) were found to be associated with hyperhomocysteinemia. There was a strong nonlinear increase in the serum homocysteine levels across the quartiles of cotinine. Multivariate analysis showed that age, male gender, non-Caucasian, low levels of folate and vitamin B12, and increased serum cotinine (quartile II-IV) were independently associated with elevated homocysteine levels. In conclusion, these findings indicate that passive smoke exposure in never-smokers is positively and independently associated with plasma homocysteine levels in a dose-dependent manner. These findings may help further determine the link between passive smoking and cardiovascular events. (Int Heart J 2010; 51: 183-187)

Key words: Passive smoker, Cotinine, Homocysteine

$\mathrm{N}$ onsmokers exposed to passive smoking are at increased risk of both fatal and nonfatal cardiac events. ${ }^{1-4)}$ In 1992, the American Heart Association concluded that the risk of death due to heart disease is increased by about $30 \%$ in those exposed to environmental tobacco smoke at home, and that this risk could be much higher for people exposed at the workplace, where higher levels of environmental tobacco smoke may be present. ${ }^{5)}$ Plasma cotinine levels can objectively provide a measure of tobacco smoke exposure in nonsmokers.

Cigarette smoking is associated with increased plasma levels of homocysteine, ${ }^{7-12)}$ and both are associated with an increased risk of cardiovascular disease. Smokers also tend to have lower levels of folate, vitamin B6, and vitamin $\mathrm{B} 12,{ }^{10,12)}$ which are cofactors (vitamins B6 and B12) or cosubstrates (folate) for enzymes that control homocysteine metabolism. ${ }^{13,14)}$ Despite these observations, little is known about the effects of homocysteine on the risk of cardiovascular disease in nonsmokers.

The present study examined whether serum cotinine as a measure of passive smoke exposure in nonsmokers was associated with circulating levels of homocysteine and other inflammatory markers of cardiovascular disease risk in a general population.

\section{MethodS}

Study design: The Third National Health and Nutrition Survey (NHANES III) was designed to examine a nationally representative sample of the US noninstitutionalized civilian population between 1988 and 1994. The survey used complex, stratified, multistage probability cluster sampling. Weights indicating the probability of being sampled were assigned to each individual, enabling analyses in which results represent the entire population. The NHANES III data collection included a home interview and a detailed clinical examination in a mobile examination center. The present study used the data of 3,232 NHANES III participants (age $\geq 20$ years) who self-reported as never-smokers and had available both cotinine and homocysteine values. The NHANES III survey was approved by the Institutional

From the ${ }^{1}$ Division of Cardiology, Department of Internal Medicine, College of Medicine, The Catholic University of Korea, Seoul, Republic of Korea Address for correspondence: Hee-Yeol Kim, MD, Bucheon St. Mary's Hospital, Sosa-Dong, Wonmi-Gu, Bucheon, Kyeonggi-Do 420-717, Korea. Received for publication October 14, 2009.

Revised and accepted February 8, 2010 
Review Board of the National Center for Health Statistics, and informed consent was obtained before participation.

Laboratory measurements: Serum cotinine levels were measured using high-performance liquid chromatography in tandem with mass spectrometry. Cotinine levels were categorized into quartiles: $<0.055 \mathrm{ng} / \mathrm{mL}, 0.055-0.124 \mathrm{ng} / \mathrm{mL}$, $0.125-0.369 \mathrm{ng} / \mathrm{mL}$, and $>0.369 \mathrm{ng} / \mathrm{mL}$. To minimize the inclusion of misclassified current smokers in our sample, we excluded anyone with a value of serum cotinine $>15$ $\mathrm{ng} / \mathrm{mL}$.

C-reactive protein (CRP) levels were measured using latex-enhanced nephelometry. Since 2,044 (63.2\%) participants had CRP levels below the lowest detectable level $(0.22$ $\mathrm{mg} / \mathrm{dL}$ ), for analytical purposes the CRP level was treated as a categorical variable rather than a continuous variable. Fibrinogen levels were measured in all participants using enzyme assay methods.

Plasma homocysteine levels were measured using high-performance liquid chromatography. Homocysteine concentrations were measured between 1991 and 1994 (during phase 2 of the NHANES III). An elevated homocysteine level was defined as a concentration $>$ the $80^{\text {th }}$ percentile (cutoff value: $11.1 \mu \mathrm{mol} / \mathrm{L}$ ). The levels of vitamin
B12 and folate were measured using radioimmunoassays, and reduced folate and vitamin B12 levels were defined as a concentration $<$ the $20^{\text {th }}$ percentile (cutoff value: $7.7 \mathrm{nmol} / \mathrm{L}$ and $239.8 \mathrm{pmol} / \mathrm{L}$, respectively).

The study also examined leukocyte and platelet counts, and the levels of total serum cholesterol, high-density lipoprotein (HDL), low-density lipoprotein (LDL), triglycerides, and lipoprotein (a).

Statistical analysis: The baseline characteristics of the study participants in cotinine quartiles II, III, and IV were compared with those in quartile I using $\chi^{2}$-tests for binary variables and $t$-tests for continuous variables. The MantelHaenszel test was used to determine any trend. We performed a weighted multiple linear regression analysis with one degree of freedom as a test for any trend (Figure). We adjusted for age, gender, body mass index (BMI), race, and the levels of folate and vitamin B12 to determine their potential effects on homocysteine levels (Table III). We used multiple linear regressions to determine any independent effects of age, gender, race, BMI, levels of folate and vitamin B12, CRP level and cotinine quartile on homocysteine levels (Table IV). Statistical analyses were carried out in STATA version 8.0 (Stata Corp, College Station, TX) using

Table I. Baseline Characteristics and Laboratory Profiles

\begin{tabular}{lcccc}
\hline \multirow{2}{*}{ Variable } & \multicolumn{4}{c}{ Quartile groups of cotinine } \\
\cline { 2 - 5 } & I & II & III & IV \\
\hline Age, years & $51.4 \pm 20.6$ & $45.2 \pm 18.8^{*}$ & $43.2 \pm 18.3^{*}$ & $38.4 \pm 16.9^{*}$ \\
Male gender, \% & 20.7 & $28.7^{*}$ & $36.3^{*}$ & 38.7 \\
Caucasian, \% & 81.8 & $70.8^{*}$ & $59.7^{*}$ & $46.5^{*}$ \\
BMI, $\mathrm{kg} / \mathrm{m}^{2}$ & $27.3 \pm 5.6$ & $27.5 \pm 6.1$ & $28.0 \pm 6.2$ & $28.1 \pm 6.9^{*}$ \\
DM, \% & 11.3 & $7.6^{*}$ & $6.6^{*}$ & $4.7^{*}$ \\
SBP, $\mathrm{mmHg}$ & $126.4 \pm 20.8$ & $123.3 \pm 20.1^{*}$ & $123.2 \pm 18.9^{*}$ & $122.2 \pm 19.0^{*}$ \\
DBP, $\mathrm{mmHg}$ & $73.2 \pm 9.9$ & $73.5 \pm 10.3$ & $74.5 \pm 10.8$ & $74.9 \pm 10.7^{*}$ \\
Cotinine, $\mathrm{ng} / \mathrm{mL}$ & 0.035 & 0.084 & 0.200 & 0.804 \\
Glucose, $\mathrm{mmol} / \mathrm{L}$ & $5.7 \pm 2.3$ & $5.6 \pm 2.0$ & $5.4 \pm 1.6^{*}$ & $5.5 \pm 2.0$ \\
Folate, $\mathrm{nmol} / \mathrm{L}$ & $20.0 \pm 15.6$ & $16.4 \pm 12.0^{*}$ & $15.4 \pm 13.5^{*}$ & $13.3 \pm 9.7^{*}$ \\
Vitamin B12, $\mathrm{pmol} / \mathrm{L}$ & $450.9 \pm 1113.5$ & $428.2 \pm 1060.4$ & $383.3 \pm 300.5$ & $417.6 \pm 1348.0$ \\
\hline
\end{tabular}

Continuous variables are shown as mean $\pm \mathrm{SD}$, except cotinine (median value).

$P<0.05$ compared with the first quartile group. BMI indicates body mass index; DM, diabetes mellitus; SBP, systolic blood pressure; and DBP, diastolic blood pressure.

Table II. Levels of Inflammatory Markers and Lipid Profiles

\begin{tabular}{lcccc}
\hline & \multicolumn{4}{c}{ Quartile groups of cotinine } \\
\cline { 2 - 5 } Variable & $\mathrm{I}$ & $\mathrm{II}$ & $\mathrm{III}$ & $\mathrm{IV}$ \\
\hline $\mathrm{WBC}, \times 10^{3} / \mu \mathrm{L}$ & $7.2 \pm 3.0$ & $7.0 \pm 2.0$ & $6.8 \pm 2.0^{*}$ & $6.9 \pm 2.1^{*}$ \\
$\mathrm{PLT}, \times 10^{3} / \mu \mathrm{L}$ & $263.6 \pm 66.3$ & $262.6 \pm 70.0$ & $266.6 \pm 67.6$ & $273.5 \pm 71.1^{*}$ \\
Fibrinogen, $\mathrm{mg} / \mathrm{dL}$ & $309.0 \pm 67.5$ & $314.5 \pm 76.4$ & $307.8 \pm 77.6$ & $315.5 \pm 90.3$ \\
Homocysteine, $\mu \mathrm{mol} / \mathrm{L}$ & $8.8 \pm 4.2$ & $9.2 \pm 4.5$ & $9.3 \pm 4.7$ & $9.1 \pm 4.4$ \\
$\mathrm{CRP}>0.21 \mathrm{mg} / \mathrm{dL}$ & $39.2 \%$ & $39.7 \%$ & $32.9 \%^{*}$ & $35.2 \%$ \\
$\mathrm{CRP}>1.0 \mathrm{mg} / \mathrm{dL}$ & $9.1 \%$ & $9.4 \%$ & $6.4 \%^{*}$ & $9.8 \%$ \\
Cholesterol, $\mathrm{mmol} / \mathrm{L}$ & $5.4 \pm 1.2$ & $5.3 \pm 1.1^{*}$ & $5.2 \pm 1.2^{*}$ & $5.0 \pm 1.0^{*}$ \\
$\mathrm{HDL}, \mathrm{mmol} / \mathrm{L}$ & $1.4 \pm 0.4$ & $1.3 \pm 0.4$ & $1.3 \pm 0.4$ & $1.3 \pm 0.4$ \\
LDL, $\mathrm{mmol} / \mathrm{L}$ & $3.4 \pm 1.0$ & $3.2 \pm 0.9$ & $3.1 \pm 0.9^{*}$ & $3.1 \pm 0.9^{*}$ \\
Triglycerides, $\mathrm{mmol} / \mathrm{L}$ & $1.7 \pm 1.3$ & $1.6 \pm 1.4$ & $1.5 \pm 1.2^{*}$ & $1.3 \pm 0.9^{*}$ \\
Lipoprotein $(\mathrm{a}), \mathrm{mg} / \mathrm{dL}$ & $0.27 \pm 0.28$ & $0.29 \pm 0.28$ & $0.30 \pm 0.27$ & $0.33 \pm 0.29^{*}$ \\
\hline
\end{tabular}

WBC indicates white blood cell; PLT, platelet; CRP, C-reactive protein; HDL, high density lipoprotein; and LDL, low density lipoprotein. ${ }^{*}: P<0.05$ compared with the first quartile group. 
Table III. Relative Odds of Having an Elevated Level of Homocysteine

\begin{tabular}{lcccc}
\hline \multirow{2}{*}{ Regression } & \multicolumn{3}{c}{ Quartile of cotinine } & \multirow{2}{*}{ P for trend } \\
\cline { 2 - 5 } & II & III & IV & \\
\hline Crude & 1.15 & $1.28^{*}$ & 1.13 & 0.252 \\
& $(0.90,1.48)$ & $(1.01,1.64)$ & $(0.88,1.44)$ & \\
Model A & $1.40^{*}$ & $1.59^{*}$ & $1.60^{*}$ & $<0.001$ \\
& $(1.08,1.83)$ & $(1.22,2.07)$ & $(1.21,2.12)$ & \\
Model B & 1.29 & $1.44^{*}$ & $1.39^{*}$ & $<0.001$ \\
& $(0.97,1.70)$ & $(1.09,1.90)$ & $(1.04,1.86)$ & \\
\hline
\end{tabular}

Each cell contains the relative odds $(95 \% \mathrm{CI})$ for each variable. Reference group: quartile I. Model A: adjusted for age, gender, BMI and race. Model B: adjusted for age, gender, BMI, race, folate and vitamin B12. " $: P<0.05$ compared with the quartile I group. All $P$ values reflect a linear trend in the row values from cotinine quartiles I to IV.

Table IV. Multivariate Logistic Regression Analysis for Elevated Homocysteine

\begin{tabular}{lcr}
\hline Variable & $\begin{array}{c}\text { Odds ratio } \\
(95 \% \mathrm{CI})\end{array}$ & $P$ \\
\hline Age & $1.05(1.04-1.05)$ & $<0.001$ \\
Male & $2.30(1.87-2.81)$ & $<0.001$ \\
Caucasian & $0.75(0.60-0.94)$ & 0.013 \\
BMI & $0.99(0.97-1.01)$ & 0.458 \\
Low folate & $4.09(3.24-5.15)$ & $<0.001$ \\
Low Vit-B12 & $2.99(2.41-3.69)$ & $<0.001$ \\
CRP $>0.21 \mathrm{mg} / \mathrm{dL}$ & $0.95(0.75-1.18)$ & 0.641 \\
CRP $>1.0 \mathrm{mg} / \mathrm{dL}$ & $0.78(0.53-1.15)$ & 0.209 \\
Quartiles of Cotinine & & \\
$\quad$ II & $1.40(1.06-1.85)$ & 0.019 \\
$\quad$ III & $1.60(1.21-2.12)$ & 0.001 \\
$\quad$ IV & $1.55(1.15-2.09)$ & 0.004
\end{tabular}

: defined as a concentration $<$ the $20^{\text {th }}$ percentile. BMI indicates body mass index and CRP, C-reactive protein.

methods that were used to incorporate population weights for NHANES III. Continuous variables are shown as mean $\pm \mathrm{SD}$, unless otherwise indicated.

\section{RESUlts}

Baseline characteristics and laboratory profiles based on serum cotinine concentration quartiles are summarized in Table I. The following patient characteristics were found to be more common in the higher cotinine quartiles than in the first cotinine quartile: young age, male, non-Caucasian, high BMI, nondiabetic, low systolic blood pressure, high diastolic blood pressure, and low level of glucose and folate.

Inflammatory markers were analyzed according to cotinine quartiles (Table II). Compared with the first quartile, white blood cell counts were lower in the third and fourth quartile, and platelet counts and lipoprotein (a) levels were higher in the fourth quartile. The levels of cholesterol were lower in the second, third and fourth quartile. The levels of LDL and triglyceride were lower in the third and fourth quartile.

Conditional logistic regression analysis was performed

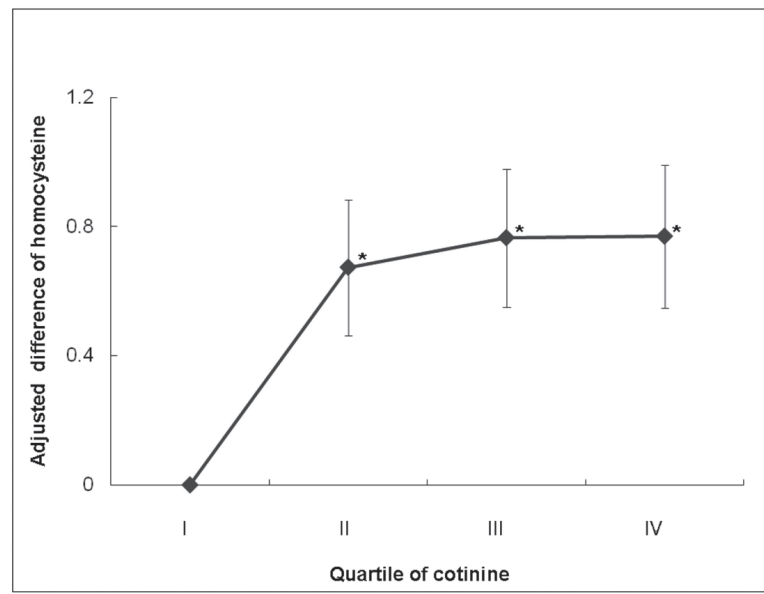

Figure. Linear trend in the relationship between cotinine quartiles and adjusted homocysteine concentration. " $P<0.001$ compared with the first quartile group.

to determine the odds ratios for an increased homocysteine level in the cotinine quartiles. The odds ratios were adjusted sequentially for age, gender, BMI and race, and finally for the levels of folate and vitamin B12. After adjustment for folate and vitamin B12 levels, regression analysis showed there was a positive relationship between increased homocysteine levels and increasing cotinine quartiles (Table III).

The Figure shows the adjusted mean difference in the homocysteine level across the quartiles of cotinine, by using the $\beta$-coefficient after being adjusted for age, gender, BMI, and race $(P$ for trend $<0.001)$.

Multivariate analysis showed that age, male gender, non-Caucasian, low folate, low vitamin B12, and elevated serum cotinine (quartile II, III and IV) were independently associated with an increased homocysteine level (Table IV).

\section{Discussion}

This is the first study to identify a positive, independent, dose-response relationship between passive tobacco smoke exposure and plasma homocysteinemia, in which cotinine concentration was used as a measure of exposure.

Cigarette smoking is established as a major risk factor for coronary heart disease. This effect is caused by various factors such as sympathetic activation and inflammation. ${ }^{15,16)}$ It has already been showed that passive smoking was linked to cardiovascular events, and in that study being a passive smoker was determined by interview alone. ${ }^{2)}$ In addition, while a recent study used cotinine levels as a measure of passive tobacco smoke exposure, it showed a positive relationship between coronary heart disease, not stroke, and cotinine level, but it did not investigate the relationship between passive smoke exposure and homocysteine level. ${ }^{17)}$

Although living with a smoker is an important factor in passive smoking, it accounts for less than half of the variation in the cotinine concentration among nonsmokers and it does not account for additional exposure in the workplace and in public places. ${ }^{18)}$ Measuring serum cotinine is neces- 
sary for an accurate assessment of smoking exposure. Nicotine is a major constituent of tobacco and undergoes extensive oxidative metabolism in the human liver. The main pathway for nicotine metabolism is C-oxidation to cotinine. ${ }^{19)}$ Cotinine is a highly sensitive and specific marker of active and passive exposure to tobacco, ${ }^{20)}$ and its stability in the serum over long periods has been demonstrated. ${ }^{21)}$

The mechanisms by which passive smoking increases the risk of heart disease are multiple and complex. Increased homocysteine levels are a cause of cardiovascular disease. $^{22,23)}$ Increased homocysteine alone or in combination with smoking has detrimental effects on the cardiovascular system. A plasma homocysteine and cardiovascular risk profile study conducted in Norway identified a positive association between increased homocysteine levels in the plasma and a number of cardiovascular risk factors, particularly smoking. ${ }^{7)}$ The results of a study by O'Callaghan and colleagues showed cigarette smokers with a high homocysteine level had a 12-fold increased risk of cardiovascular disease compared with nonsmokers with a normal plasma homocyteine level. ${ }^{24)}$

The precise reasons why smokers have increased plasma homocysteine levels remain unknown. The present study revealed that more exposure to smoking was responsible for higher levels of plasma homocysteine. While this could be a direct effect of passive smoking, it more likely reflects the different nutritional statuses of nonsmokers. Subar, et al studied food and nutrient intake in smokers and nonsmokers using NHANES II data. They found that smokers had a lower intake of most vitamins and were less likely to have consumed fruit, vegetables, and vitamin and mineral supplements. ${ }^{25)}$ A negative relationship between passive smoking and plasma vitamin profile was noted in the PEP study. ${ }^{26)}$ Despite the much lower exposure to tobacco smoke of passive smokers compared with smokers, passive smokers also showed a lower vitamin intake than nonsmokers. In the present study, nonsmokers exposed to high levels of smoke had a lower intake of folate than nonsmokers exposed to low levels of smoke (Table I). However, after adjusting for nutrient levels, exposure to smoke in nonsmokers was still found to positively correlate with homocysteine levels (Table III).

The present study found that the highest and lowest cotinine quartile concentrations differed more than 20-fold. This range seems to be considerably wider than what might be expected from a nonsmoker who lives with a partner who smokes. According to the NHANES III survey, $37 \%$ of people ( $46 \%$ of men and $32 \%$ of women) were exposed to smoke; $11 \%$ of this exposure was at home, $20 \%$ at work, and $6 \%$ at both home and work. ${ }^{27)}$ The high prevalence of passive smoking in the general population has implications for public health. The only safe way to protect nonsmokers from exposure to cigarette smoke is to eliminate smoking from public places, workplaces, and the home.

This study has some strengths. First, we excluded nonsmokers with a past smoking history (ex-smokers). Because precise mechanisms about increased homocysteine levels in passive smokers are not known, the influence of past smoking could not be eliminated. Second, measurement of cotinine may reduce the misclassification among self-reported nonsmokers in epidemiologic studies. Previ- ous studies have used a range of the serum cotinine level $(10-15 \mathrm{ng} / \mathrm{mL})$ as a cutoff point for discriminating between the current smokers and the nonsmokers. ${ }^{28)}$ To minimize the inclusion of misclassified current smokers in our study, we excluded anyone with a value of serum cotinine $>15$ $\mathrm{ng} / \mathrm{mL}$. The current study also had a limitation. The crosssectional design did not allow us to determine the temporal relationship between passive smoke exposure and the increases in risk factors.

In conclusion, these findings indicate that passive smoke exposure in never-smokers is associated with plasma homocysteine levels in a positive, independent, and dosedependent manner. These findings may support why passive smoking is a risk factor for cardiovascular events.

\section{REFERENCES}

1. Garland C, Barrett-Connor E, Suarez L, Criqui MH, Wingard DL. Effects of passive smoking on ischemic heart disease mortality of nonsmokers. A prospective study. Am J Epidemiol 1985; 121: 645-50.

2. Kawachi I, Colditz GA, Speizer FE, et al. A prospective study of passive smoking and coronary heart disease. Circulation 1997; 95: 2374-9.

3. Law MR, Morris JK, Wald NJ. Environmental tobacco smoke exposure and ischaemic heart disease: an evaluation of the evidence. BMJ 1997; 315: 973-80.

4. He J, Vupputuri S, Allen K, Prerost MR, Hughes J, Whelton PK. Passive smoking and the risk of coronary heart disease -a meta-analysis of epidemiologic studies. N Engl J Med 1999; 340: 920-6.

5. Taylor AE, Johnson DC, Kazemi H. Environmental tobacco smoke and cardiovascular disease. A position paper from the Council on Cardiopulmonary and Critical Care, American Heart Association. Circulation 1992; 86: 699-702.

6. Curvall M, Vala EK, Enzell CR, Wahren J. Simulation and evaluation of nicotine intake during passive smoking: cotinine measurements in body fluids of nonsmokers given intravenous infusions of nicotine. Clin Pharmacol Ther 1990; 47: 42-9.

7. Nygård $\mathrm{O}$, Vollset SE, Refsum H, et al. Total plasma homocysteine and cardiovascular risk profile. The Hordaland Homocysteine Study. JAMA 1995; 274: 1526-33.

8. Nygård O, Refsum H, Ueland PM, Vollset SE. Major lifestyle determinants of plasma total homocysteine distribution: the Hordaland Homocysteine Study. Am J Clin Nutr 1998; 67: 263-70.

9. El-Khairy L, Ueland PM, Nygård O, Refsum H, Vollset SE. Lifestyle and cardiovascular disease risk factors as determinants of total cysteine in plasma: the Hordaland Homocysteine Study. Am J Clin Nutr 1999; 70: 1016-24.

10. McCarty MF. Increased homocyst(e)ine associated with smoking, chronic inflammation, and aging may reflect acute-phase induction of pyridoxal phosphatase activity. Med Hypotheses 2000; 55: 289-93.

11. Reis RP, Azinheira J, Reis HP, Pina JE, Correia JM, Luís AS. Influence of smoking on homocysteinemia at baseline and after methionine load. Rev Port Cardiol 2000; 19: 471-4.

12. Pagán K, Hou J, Goldenberg RL, Cliver SP, Tamura T. Effect of smoking on serum concentrations of total homocysteine and B vitamins in mid-pregnancy. Clin Chim Acta 2001; 306: 1039.

13. Vermaak WJ, Barnard HC, Potgieter GM, Theron HD. Vitamin B6 and coronary artery disease. Epidemiological observations and case studies. Atherosclerosis 1987; 63: 235-8.

14. Robinson K, Mayer EL, Miller DP, et al. Hyperhomocysteinemia and low pyridoxal phosphate. Common and independent 
reversible risk factors for coronary artery disease. Circulation 1995; 92: 2825-30.

15. Shinozaki N, Yuasa T, Takata S. Cigarette smoking augments sympathetic nerve activity in patients with coronary heart disease. Int Heart J 2008; 49: 261-72.

16. Katayama T, Iwasaki Y, Sakoda N, Yoshioka M. The etiology of 'smoker's paradox' in acute myocardial infarction with special emphasis on the association with inflammation. Int Heart $\mathrm{J}$ 2008; 49: 13-24.

17. Whincup PH, Gilg JA, Emberson JR, et al. Passive smoking and risk of coronary heart disease and stroke: prospective study with cotinine measurement. BMJ 2004; 329: 200-5.

18. Jarvis MJ, Foulds J, Feyerabend C. Exposure to passive smoking among bar staff. Br J Addict 1992; 87: 111-3.

19. Benowitz NL, Jacob P, 3rd, Perez-Stable E. CYP2D6 phenotype and the metabolism of nicotine and cotinine. Pharmacogenetics 1996; 6: 239-42.

20. Benowitz NL. Cotinine as a biomarker of environmental tobacco smoke exposure. Epidemiol Rev 1996; 18: 188-204. (Review)

21. Jarvis MJ, Goddard E, Higgins V, Feyerabend C, Bryant A, Cook DG. Children's exposure to passive smoking in England since the 1980s: cotinine evidence from population surveys. BMJ 2000; 321: 343-5.

22. Dalery K, Lussier-Cacan S, Selhub J, Davignon J, Latour
Y, Genest J Jr. Homocysteine and coronary artery disease in French Canadian subjects: relation with vitamins $\mathrm{B}_{12}, \mathrm{~B}_{6}$, pyridoxial phosphate, and folate. Am J Cardiol 1995; 75: 1107-11.

23. Blacher J, Benetos A, Kirzin JM, Malmejac A, Guize L, Safar ME. Relation of plasma total homocysteine to cardiovascular mortality in a French population. Am J Cardiol 2002; 90: 5915.

24. O'Callaghan P, Meleady R, Fitzgerald T, Graham I. Smoking and plasma homocysteine. Eur Heart J 2002; 23: 1580-6.

25. Subar AF, Harlan LC, Mattson ME. Food and nutrient intake differences between smokers and non-smokers in the US. Am J Public Health 1990; 80: 1323-9.

26. Tröbs M, Renner T, Scherer G, et al. Nutrition, antioxidants, and risk factor profile of nonsmokers, passive smokers and smokers of the Prevention Education Program (PEP) in Nuremberg, Germany. Prev Med 2002; 34: 600-7.

27. Pirkle JL, Flegal KM, Bernert JT, Brody DJ, Etzel RA, Maurer KR. Exposure of the US population to environmental tobacco smoke: the Third National Health and Nutrition Examination Survey, 1988 to 1991. JAMA 1996; 275: 1233-40.

28. Wagenknecht LE, Burke GL, Perkins LL, Haley NJ, Friedman GD. Misclassification of smoking status in the CARDIA Study: a comparision of self-report with serum cotinine levels. Am J Public Health 1992; 82: 33-6. 